that all advance in scientific knowledge has a bearing on the "business" life of a country, and we believe that these hints, based on the practical experience acquired at the Chesapeake Zoological Laboratory, will not be without value as showing what the man of science may do for the man of business. -(Fohns Hopkins University Circulars, vol. v., No. 43, p. Io, Baltimore, October I885.

\section{REPORT OF THE SUPERINTENDENT OF} THE U.S. NAVAL OBSERVATORY ${ }^{1}$

WE make the following extracts from this important Report :-

Rear-Admiral S. R. Franklin, U.S.N., continued in the duties of Superintendent until March 3I of the current year, when he was detached therefrom in order to assume command of the United States naval force on the European station. In the interim from that date until June I, I885, Commander A. D. Brown, U.S.N., acted as Superintendent, when, under the orders of the Department, Commodore Belknap assumed the duties of the office.

The 26-inch Equatorial.-This telescope has continued in charge of Prof. A. Hall, U.S.N., who has been employed in observing the satellites of the large planets and in observation of double stars.

Though in constant use, the instrument, together with its micrometer, driving clock, and other apparatus, remains in good working order, and the dome, forty-three feet in diameter, covering it, is now revolved with great ease by means of the four horse-power gas-engine which was connected with it in the latter part of 1884 . The dome is now turned to any position required in a few minutes, and the work of observing is much facilitated. Mr. George Anderson has charge of the engine, and assists Prof. Hall in the management of the dome.

The complete reduction and discussion of the observations made with this instrument have made good progress during the past year. This is due, in a great measure, to the efficient aid rendered by Lient. W. H. Allen and Ensign J. A. Hoogewerff, U.S.N. These gentlemen have been very diligent in making the necessary computations, and have shown marked aptitude for the work.

The observations of the satellite of Neptune and those of the two outer satellites of Uranus have been discussed, and the masses of these planets deduced. These results have been published in Appendixes I. and II. of the annual volume of the Observatory for the year I88I.

A discussion of all the observations of Iapetus, the outer satellite of Saturn, is now nearly finished, and will be ready for printing in a few weeks. . .

The Prime Vertical Instrument.-The work of reducing the observations made in $1883-84$ by Lieut. C. G. Bowman and Ensign H. Taylor, U.S.N., for the determination of the constant of aberration, has been pursued. A selection was made of twelve stars of varying right ascension and well-determined places, and the results obtained; the reduction of the remaining observations will be proceeded with as rapidly as possible.

In July of last year a communication was received from the President of the International Geodetic Conference, asking the co-operation of this Observatory with the Royal Observatory at Lisbon in the determination of the problem of the change of latitudes, the observations to be taken with the prime vertical instruments of the two Observatories. Communication was opened and correspondence is still in progress with the Director of the Observatory at Lisbon, and preparations have be $n$ made to undertake the work here very soon after it is known that it will be begun at Lisbon. . .

Photography. - In the programme of work proposed for the current year it was stated that the work of taking sun photographs daily would be inaugurated as soon as practicable. The work of the Transit of Venus Commission has up to this time prevented any regular system being adopted. Such work, if pursued systematically and continuously, would put this institution on a footing in this regard more nearly equal to that of the larger foreign Observatories where a large mass of data has been accumulated for future measurement, computation, and discussion, forming the basis of much information of value to the student of solar physics.

For purposes of co-operation in this scientific work, photographic observations in different parts of the world being sup-

${ }^{1}$ By G. E. Belknap, Commodore U.S.N., Superintendent United States Naval Observatory. Dated Washington, October 5, 1885 plemental to each other, it is also desirable that this work be begun, and sooner or later it will have to be taken up here in order to keep pace with the requirements of modern astronomical research and observation. It cannot, therefore, be begun too soon.

It is eminently desirable that this Observatory possess a collection of photographs of astronomical subjects, and so be enabled to solicit exchanges from astronomers abroad that are engaged in celestial photography. But we lack the means and equipment for printing and making photographic positives that can properly be used for such purposes of exchange.

Much work is desirable to be done in photographing star clusters, nebula, and the spectra of sun-spots, stars, \&c., and in the production of star maps by photography. Should a party from this Observatory be sent to observe the total eclipse of 1886, photographs of the phenomenon will have to be taken. The Observatory should at all times be prepared for such an occasion and have a staff drilled in photographic work, and this might be easily accomplished, as the number need not be great, and it could be made up of officers stationed here.

New Obserzaiury.- - The Commodore renews the recommendations of his predecessors for the removal, at an early day, of the plant of the Observatory to the new site selected and purchased for such purpose in 1881 .

The plans, long since prepared, have received the approval of prominent scientific men of the country, and the work can be begun as soon as the money is forthcoming; and with the funds in hand, it would take fully three years to erect the buildings, transfer the plant, and get everything into good working order.

The National Academy has been requested by the Department to express its opinion officially as to the advisability of proceeding promptly with the erection of the building, and it cannot be doubted that it will express itself affirmatively in the matter.

The disadvantages of the present location have been so often and so forcibly described that the subject is worn almost threadbare.

To the foresight and energy of officers of the Navy is due the inception and development of this institution. It is emphatically the child of the Navy, and the service is much interested in its welfare and in every effort to extend the sphere of its usefulness. From its humble beginning in 1838 it has now grown to be one of the most important astronomical centres in the world, and it is to be hoped that Congress will recognise the good work hitherto done by granting the means to place the institution on a still higher plane than it now occupies.

Board of Visitors. - The Commodore renews the suggestion heretofore made that a Board of Visitors, c mmposed of competent persons, be appointed annually to visit the institution and inquire into its working, with authority to suggest such changes in the methods pursued, or such new lines of investigation, as it might deem proper to recommend.

Solar Eclipse of 1836. - A total eclipse of the sun will occur on August 29, 1886. The line of totality passes over the equatorial portion of the $A$ tlantic Ocean, and reaches the west coast of Africa, near Benguela, in latitude $12^{\circ} \mathrm{S}$. This port is easy of access, and as it is the healthy season, there would be no difficulty in sending a party out in a Government vessel. The duration of the totality at this point is four minutes and forty seconds, affording a more than usually gond opportunity for photographic and spectroscopic observations. The question as to the propriety of applying for an appropriation to defray the expenses of an observing party has been referred by the Department to the National Academy, and a report may soon be expected.

Miscellancous.-During the year the names of 1408 visitors have been recorded, and II 37 permi's were issued for night visitors, for whose accommodation the small equatorial is set apart. The presence of these visitors is not allowed to interfere with the regular work of the institution, and permits are only issued for one evening in each week, with exceptional instances.

The records kept by the several observers and watchmen show that only about one night in eight is good for observing, while an exceptionally good night for astronomical work cannot be reckoned upon much oftener than once a month.

\section{MOLECULAR PHYSICS}

$A^{T}$ the meeting of the Berlin Physical Society, on Nov, 20 last, Herr Gerstmann spoke on a work recently issued by Prof. W. C. Wittwer, on "The Principles of Molecular Physics 
and Mathematical Chemistry." The main problem to which the work addressed itself respected the nature and properties of the imponderable matter, ether, but its arguments were, in the main, drawn from fancy more than from experience. The work was divided into three parts. The first part, the Constitution of Bodies, formulated the theory that the ponderable atoms were not qualitatively, but only quantitatively, distinguished from one another; that the elastic effect of matter on ether, as on ponderable substances, diminished with the distance; and that the density of the ether ranged round ponderable matter did not diminish in proportion to the distance from the mass of atoms, but increased in proportion to the distance. As essential to the constitution of the bodies was further advanced the pressure of ether on the particles of ether ranged round the ponderable atoms. The second part, the Principles of Chemis try, proceeded from the hypothesis that a material particle was capable of attracting only one, or quite few, particles of ether, acting in such a manner, namely, that a fraction of the attractive force, now of the particle of ether, now of the mass particle, was kept in abeyance (conditions which, for reasons otherwise altogether unexplained, were termed "electro-negative" and "electro-positive" respectively), and made use of an accidental property of the curve of the density of elements contained in L. Meyer's "Modern Theory of Chemistry," namely, that in the case of the maxima and minima of this curve, elements related electro-negatively to the neighbouring elements in the curve always passed over to such in which the reverse condition obtained. in order, by calculations described by the author himself as highly uncertain, to determine the molecular magnitude of some elements and the number of particles of ether attracted by their atoms. The third part, the Doctrine of Heat, propounded heat as elastic concussions ; in elaborate calculations brought forward for some examples of numbers the argument that the occurrence of the stationary state was explainable under this assumption likewise; and contended against the MariotteGay-Lussac and Avogadrolaws, which were incapable of rightly explaining the facts, seeing that these laws and their deduction took no account whatever of the imponderable ether and the pressure of ether.

\section{THE HISTCRY OF FOSSIL CROCODILES 1}

$\mathrm{IN}$ this communication the author endeavoured to summarise the main facts already known regarding the palæontological history of the Crocodilia, with full references to the principal literature of the subject. After some preliminary remarks upon the structure and distribution of the living members of the order, the leading types of each geological period were successively considered ; and the paper concluded by discussing the bearing of these facts upon the evolution of the Crocodilia, as determined by Prof. Huxley in 1875 . The earliest crocodilians hitherto discovered are Belodm, Stagonolepis, and Parasuchus, from the Upper Trias--the first-named being met with on the Continent, in India, and in North America; the second, solely known from the yellow sandstones of Elgin; and the third, only recorded as yet from India. The Rhatic Beds and Lower and Middle Lias do not appear to have yielded any remains of this order, but numerous examples have been found in the Upper Lias, and some in a remarkable state of preservation. At present, however, the precise systematic relationships of the Liassic forms have not been very satisfactorily deter. mined, and those from British cleposits are especially in need of further study: there are probably two generic types, Mystriosaurus and Pelaoosaurus, and, if the latest researches are to be followed, it would seem that only two species of each are definitely known. In England, according to M. Deslongchamps, two distinct forms, Mystriosaurus chap. mani and Pelagosaurus brongniarti, have been continually described under the name of Teleosaurus chapmani. With the Lower Oolites, Teleosaurus proper makes its appearance, and ranges at least as far upwards as the Kimmeridge Clay, from which Mr. J. W. Hulke has described a characteristic snout (T. megarhinus). Steneosaurus is also a Lower Oolite form, ranging to the Oxford Clay ; its British representatives are somewhat imperfectly known, though very complete descriptions have been published of well-preserved cranial fossils from French deposits. Metriorlunnchus is another genus, from the Middle

' Abstract of a Paper read at the meeting of the Geologists' Association on December 4, 1885, by Mr. A. Smith Woodward, F.G.S., of the British Museum (Natural History). and Upper Oolites, very fully elucidated by M. Deslongchamps in France, but scarcely determined hitherto in English strata. Two forms described by Prof. Phillips under the names of Steneosaurus falpebrosus (Kimmeridgian), and Steneosaurus gra. cilis (Portlandian) are truly referable to Metriorhynchus, and fragments agreeing specifically with some of the French Metriorhynchs are also recorded. The Upper Oolites also yield the remains of Crocodilia with comparatively short and stout skulls, and very complete specimens have been discovered in the Kimmeridge Clay both of England and the Continent. They belong to the genera Dakosaurus and Mashimosazurus, the former having also been described by Sir Richard Owen under the name of Plesiosuchus. Teleosaurians occur rarely in the Wealden and Purbeck Beds -though one or two well-preserved crania of Macrorkynchus are known in Germany-and they finally dis. appear in the Upper Cretaceous series, where they are represented by the scanty remains of Hyposaurus and Enaliosuchus. Broad-faced crocodilians, adapted for a more terrestrial mode of life than the Teleosaurs, occur somewhat abundantly in the Wealden and Purbeck Beds, and are represented by Goniopholis, Nannosuchus, Ozeniasuchus, Theriosuchus, and a remarkably interesting genus-Bernissartia-recently described by M. Dollo from the now classical deposit of Bernissart in Belgium. The latter, though decidedly Mesosuchian, approaches the living crocodiles and alligators much more closely than any of its congeners, both in the characters of its dermal armour and in certain parts of the skull. The earliest evidence of procolian crocodiles hitherto made known is from the Cambridge Greensand and the nearly equivalent Gosau Beds of Vienna ; Prof. H. G. Seeley has described a few vertebræ, teeth, and fragments of limbbones, and regards these as referable to at least three specific types. The Upper Cretaceous beds of France and the United States bave yielded still more satisfactory remains-including skulls - howing that the Eusuchian sub-order dates back beyond Eocene times; and some of these fossils appear almost indistinguishable from the living genus Gavialis. The early Tertiary deposits, both of England and the Continent, are remarkable as affording traces of gavials, crocodiles, and alligators (or alligatoroid genera) associated together, while the three families share no common area of the earth's surface at the present time; the Eocene types, moreover, appear to be rather less differentiated than is the case in the existing fauna. In conclusion, it may be said that the abundant acquisitions of fossil Crocodilia during the last ten years have fully confirmed the views of Prof. Huxley, laid before the Geological Society in 1875; and the Wealden and Purbeck discoveries, particularly, have brought to light facts which were then little more than probable surmises based upon very fragmentary materials.

\section{PROFESSOR SYLVESTER'S LECTURE “ON} THE METHOD OF RECIPROCANTS AS CONTAINING AN EXHAUSTIVE THEORY OF THE SINGULARITIES OF CURVES"

PROFESSOR SYLVESTER sends us the following corrections and additions to his lecture recently given in NATURE (January 7, p. 222) :-

\section{Errata}

P. 223 , rst column, line 27 , for "requirements" read "acquirements."

P. 224, Ist column, line 37, for geometrical adjustment read numerical adjustment.

$$
\text { P. } 225 \text {, in the footnote, for } \frac{\eta^{\prime \prime \prime}}{\eta} \text { read } \frac{\eta^{\prime \prime \prime}}{\eta^{\prime}} \text {. }
$$

P. 226, 2nd column, line 9, p. 227, Ist column, lines 14,20 , $22,3 \mathrm{I}, 34,44$, and 2 nd column, line 16 from bottom, in all thees places for $\tau$ read $t$, and in the last for $\tau-\tau^{\prime}$ read $t-t^{\prime}$.

P. 226, 2nd column, line 5,

$$
\begin{aligned}
& \text { for } \frac{d y}{d x^{2}}, \frac{d y}{d x^{3}}, \frac{d y}{d x^{4}}, \ldots \\
& \text { read } \frac{d^{2} y}{d x^{2}}, \frac{d^{3} y}{d x^{3}}, \frac{d^{4} y}{d x^{4}}, \ldots
\end{aligned}
$$

P. 226 , 2nd column, line 20 , for "operation" read "operator." P. 228, Ist column, line $\mathrm{I}$, for $\tau$ read $t$.

P. 229, in the Ist line of the footnote in the Ist column, for "generating fraction" read "fractional generating function." 